\title{
DIAGNÓSTICO E ETIOLOGIA DE MASTITE SUBCLÍNICA EM CAPRINOS LEITEIROS
}

\section{Alana Ferreira de Barros² ${ }^{2}$ Elizabeth Simões do Amaral Alves³ ${ }^{3}$ João Manoel da Silva ${ }^{3}$, Tania Marta Carvalho dos Santos ${ }^{3}$}

\author{
${ }^{1}$ Parte do Trabalho de conclusão de curso da primeira autora. \\ 2Universidade Federal de Alagoas - UFAL. Endereço: Zona Rural, Fazenda São Luiz, S/N, Viçosa- AL. E-mail: alanamed.vet@hotmail.com. \\ ${ }^{3}$ Laboratório de Microbiologia Agrícola, Centro de Ciências Agrárias- CECA, Universidade Federal de Alagoas- UFAL. Endereço: BR- \\ 104, Rio Largo - AL, 57100-000.
}

Autores para correspondência: elizabetamaral@hotmail.com,jm.agro@hotmail.com, tmcs@ceca.ufal.br.

\begin{abstract}
RESUMO: A caprinocultura é uma atividade com relevante importância socioeconômica para a região Nordeste brasileira, sendo praticada, principalmente, por pequenos produtores e em propriedades características de agricultura familiar. A quantidade e qualidade do leite é influenciada por parâmetros zootécnicos, especialmente por meio da sanidade dos animais. Assim, aspectos microbiológicos são importantes para com a prevenção e controle de enfermidades como a mastite subclínica. Diante disso, objetivou-se por meio desse trabalho o diagnóstico da etiologia de mastite subclínica em caprinos leiteiros no Estado de Alagoas. Foram colhidas de forma aleatória, 200 amostras de leite procedentes de 100 cabras em diferentes estágios de lactação oriundas de uma propriedade leiteira do município de Coité do Nóia no estado de Alagoas, Brasil. Os animais eram da raça Saanen, Toggenburg, Parda Alpina e mestiços, em diferentes graus de sangue criados de forma intensiva. Para o diagnóstico da mastite subclínica foi aplicado o California Mastitis Test (CMT). Para o exame microbiológico foram coletados individualmente dos antímeros mamários um volume de $10 \mathrm{ml}$ em frascos com tampa rosqueável, esterilizados e previamente identificados com o número do animal. 0 isolamento bacteriano foi realizado através de plaqueamento em Ágar base acrescido de sangue ovino a 5\%. Por meio das análises foi observado que Staphylococcus spp. foi o micro-organismo predominante como agente etiológico de mastite subclínica.
\end{abstract}

Palavras-chave: Staphylococcus, sanidade animal, caprinocultura

\section{DIAGNOSIS AND ETIOLOGY OF SUBCLINICAL MASTITIS IN DAIRY GOATS}

ABSTRACT: Goat farming is an activity with relevant socioeconomic importance for the Brazilian Northeast region, being practiced, mainly, by small producers and in characteristic properties of family agriculture. The quantity and quality of milk is influenced by zootechnical parameters, especially by means of animal health. Thus, microbiological aspects are important for the prevention and control of diseases such as subclinical mastitis. Therefore, the objective of this study was to diagnose the etiology of subclinical mastitis in dairy goats in the State of Alagoas. A total of 200 milk samples from 100 goats at different stages of lactation from a dairy farm in the municipality of Coité do Nóia in the state of Alagoas, Brazil, were randomly collected. The animals were Saanen, Toggenburg, Parda Alpina and mestizos, in different degrees of blood created intensively. For the diagnosis of subclinical mastitis the California Mastitis Test (CMT) was applied. For the microbiological examination, a volume of $10 \mathrm{ml}$ was individually collected from the mammalian antigens in sterile, screw-cap bottles previously identified with the animal number. The bacterial isolation was performed by plating on base agar plus $5 \%$ sheep blood. Through the analyzes it was observed that Staphylococcus spp. was the predominant microorganism as the etiologic agent of subclinical mastitis.

Keywords: Staphylococcus, animal health, goat farming

\section{INTRODUÇÃO}

A produção de leite de cabra no Nordeste do Brasil é uma atividade de grande importância econômica, praticada por pequenos e médios produtores. Nos últimos anos, vários esforços têm sido realizados por agências governamentais em associação às Universidades para implementar programas de melhoria do nível tecnológico da indústria 
de leite de cabra. Embora a produção deste alimento tenha aumentado no Brasil, especialmente na Região Nordeste, há uma considerável lacuna de informações sobre a qualidade microbiológica do leite de cabra comercializado no País para subsidiar as necessidades da indústria (MONTE et al., 2017).

A quantidade e a qualidade do leite produzido são influenciadas por fatores relacionados com a obtenção, armazenamento e transporte do leite, fatores zootécnicos (manejo, alimentação e potencial genético dos rebanhos), assim como fatores sanitários da glândula mamária e do animal em geral. A mastite é a inflamação mais frequente em animais destinados a produção de leite e a que mais onera a pecuária leiteira (ACOSTA et al., 2016).

A mastite é a inflamação da glândula mamária em consequência principalmente de processos infecciosos, sendo caracterizada por alterações físicoquímicas e bacteriológicas do leite e patológicas do tecido glandular mamário podendo ser classificada como clínica ou subclínica pela sua aparência e de acordo com agente causador da infecção em ambiental ou contagiosa (SILVA et al., 2013).

A mastite em caprinos é predominantemente subclínica e os patógenos comumente relacionados com infecções intramamárias são Staphylococcus e Streptococcus, considerados os principais microorganismos contagiosos, além de agentes ambientais como enterobactérias e Mycoplasma spp. (ALMEIDA et al., 2013).

Contudo, é necessário atentar-se para os casos da mastite subclínica em caprinos, pois, além de serem os patógenos de maior prevalência, também podem aumentar significativamente a Contagem de Células Somáticas (CCS) e diminuir a produção de leite, dessa forma é importante a identificação das espécies para determinar sua patogenicidade e desenvolver práticas de manejo para a prevenção de mastite (SALABERRY et al., 2016).

Para o diagnóstico da mastite são citados testes indiretos como o California Mastitis Tests (CMT), Contagem eletrônica de Células Somáticas (CCS) e exame clínico, além de testes diretos como o cultivo microbiológico que é considerado o padrão outro para diagnóstico pois permite identificar o agente causador da doença (SILVA et al., 2013).

Assim, este trabalho teve como objetivo diagnosticar e identificar etiologicamente a mastite subclínica num rebanho de caprinos leiteiros através dos testes de CMT e o cultivo microbiológico.

\section{MATERIAL E MÉTODOS}

Foram colhidas de forma aleatória, 200 amostras de leite procedentes de 100 cabras em diferentes estágios de lactação oriundas de uma propriedade leiteira do município de Coité do Nóia no estado de Alagoas, Brasil. Os animais eram da raça Saanen, Toggenburg, Parda Alpina e mestiços, em diferentes graus de sangue e eram criados de forma intensiva.

Para o diagnóstico da mastite subclínica foi aplicado o California Mastitis Test (CMT), utilizando uma raquete, onde 0 leite e o reagente foram homogeneizados durante 10 segundos, observando a mistura determinada pela viscosidade formada entre 0 reagente e o leite foi anotado os escores aritméticos atribuídos de acordo com cada reação ao CMT, sendo 0 , para reações negativas, 1+ (fracamente positivas), $2+$ (positivas) e 3+ (fortemente positivas).

Para o exame microbiológico foram coletados individualmente dos antímeros mamários um volume de $10 \mathrm{ml}$ em frascos com tampa rosqueável, esterilizados e previamente identificados com o número do animal, após descarte dos três primeiros jatos e antissepsia do óstio do teto com álcool $70 \%$, os frascos foram acondicionados em caixa isotérmica com gelo e encaminhados aos laboratórios no mesmo dia.

0 isolamento bacteriano foi realizado através de plaqueamento em Ágar base acrescido de sangue ovino a $5 \%$, posteriormente as placas foram semeadas e incubadas em estufa bacteriológica em temperatura de $37^{\circ} \mathrm{C}$ por até $72 \mathrm{~h}$. Decorrido este período realizou-se a leitura para verificação de colônias e posteriormente foi realizada a técnica de coloração de Gram para determinação da morfologia dos agentes bacterianos.

Os resultados obtidos foram tabulados $e$ posteriormente analisados através das distribuições das frequências relativas e absolutas.

\section{RESULTADOS E DISCUSSÃO}

Por meio dos ensaios microbiológicos foi possível obter o perfil das amostras de leite caprino analisadas, onde se observou a relação entre 0 perfil microbiológico e o CMT (Tabela 1) mostrando que tanto para o microbiológico, quanto para o CMT, 
predominaram índices negativos quanto a presença de micro-organismos indesejáveis.

Tabela 1 - Relação entre o exame microbiológico e os escores de CMT.

\begin{tabular}{|c|c|c|}
\hline \multicolumn{3}{|c|}{ Microbiológico } \\
\hline & Positivo & Negativo \\
\hline CMT Positivo & $21,5 \%(43 / 200)$ & $59,5 \%(119 / 200)$ \\
\hline CMT Negativo & $3 \%(6 / 200)$ & $16 \%(32 / 200)$ \\
\hline
\end{tabular}

Quanto à frequência de bactérias isoladas das amostras, a prevalência foi para Staphylococcus spp. e a menor para Corynebacterium sp. (Tabela 2) ambas comumente relacionadas ao perfil microbiológico em amostras de leite caprino.

Tabela 2 - Frequência absoluta e relativa de bactérias isoladas do leite de cabra.

\begin{tabular}{ccc}
\hline Bactérias isoladas & $\mathrm{FA}(\%)^{*}$ & $\mathrm{FR}(\%)$ \\
\hline Staphylococcus spp. & 46 & 83,64 \\
Micrococcus sp. & 6 & 10,91 \\
Corynebacterium sp. & 2 & 3,64 \\
Cocos Gram negativos & 1 & 1,81 \\
& 55 & 100 \\
\hline
\end{tabular}

*FA - Frequência Absoluta; FR - Frequência Relativa.

Staphylococcus spp. tem sido descrito como um dos principais agentes etiológicos de mastite em caprinos, como evidenciado por Silva et al. (2013). Os autores destacam ainda que a alta frequência de Staphylococcus spp. nos casos de mastite é comum pois, tal micro-organismo é considerado um dos principais agentes causadores dessa enfermidade em pequenos ruminantes.

Um fator relevante no surgimento e persistência dessas bactérias causando mastite em caprinos é o uso desordenado e incorreto de antibióticos, o que vem a causar resistência nessas bactérias, o que dificulta 0 tratamento e controle das mesmas, sendo uma barreira para com a sanidade do rebanho, e consequentemente, a qualidade do leite.

\section{CONCLUSÕES}

De acordo com os dados obtidos, constata-se que a bactéria Staphylococcus spp. é predominantemente ocorrente como agente etiológico de mastite em caprinos.

\section{REFERÊNCIAS}

ACOSTA, A. C.; DA SILVA, L. B. G.; MEDEIROS, E. S.; PINHEIRO-JUNIOR, J. W.; MOTA, R. A. Mastites em ruminantes no Brasil. Pesquisa Veterinária Brasileira, 2016, 36, 565-573.

ALMEIDA, J. F.; AQUINO, M. H. C.; MAGALHÃES, H.; NASCIMENTO, E. R.; PEREIRA, V. L. A.; FERREIRA, T.; MARRETO, M. L. Principais alterações no leite por agentes causadores de mastite no Rebanho caprino dos estados de minas gerais e rio de janeiro. Arquivos do Instituto Biológico, 2013, 80 13-18.

MONTE, D. F. M.; LOPES JUNIOR, W. D.; OLIVEIRA, C. J. B.; DE MOURA, F. P. Indicadores de qualidade microbiológica de leite caprino produzido na Paraíba. Agropecuária Científica do Semiárido, 2017, 12, 354358.

SALABERRY, S. R. S.; SAIDENBERG,A.B. S.;ZUNIGA, E.; GONSALES, F. F.; MELVILLE, P. A.; BENITES, N. R. Análise microbiológica e perfil de sensibilidade do Staphylococcus spp. em mastite subclínica de caprinos leiteiros. Arquivo Brasileiro de Medicina Veterinária e Zootecnia, 2016, 68, 336-344.

SILVA, J. G.; ALVES, B. H. L. S.; KUNG, E. S.; NASCIMENTO, R. B.; FERNANDES, M. S. T. F.; BEZERRA, M. J. G.; SÁ, S. G.; RIBEIRO, M. N.; MOTA, R. A. Etiologia das Mastites em Cabras e Ovelhas de Raças Naturalizadas Criadas no Semiárido Nordestino. Medicina Veterinária, 2013, 7, 26-31. 